\title{
Spleen Soft Tissue Tumors
}

The spleen can be (rarely) affected by benign and primary malignant soft tissue tumors. From the clinical viewpoint, these lesions must be distinguished from other types of splenic neoplasms, such as lymphoid tumors (e.g., Hodgkin disease, nonHodgkin lymphomas) and secondary tumors (metastatic disease from primary malignancies arising elsewhere).

Splenomegaly is the commonest finding. Upper quadrant discomfort, pain, or tenderness may also be complained by the patient, but some cases are asymptomatic and are diagnosed incidentally during imaging studies performed for other reasons (incidentaloma). Anemia, granulocytopenia, and thrombocytopenia are also possible (hypersplenism), depending on the size of the lesion. In case of malignancy, splenomegaly may be associated with fever, cachexia, and pleural effusion.

Computed tomography scan and magnetic resonance imaging are useful but can rarely identify the nature of the splenic lesion. Since the biopsy is usually contraindicated (due to the risk of bleeding) and imaging can rarely be pathognomonic, splenectomy is often needed to make a precise diagnosis.

The following is a list of the most frequent soft tissue tumors of the spleen reported in the literature:

\begin{tabular}{l|l}
\hline Hemangioma & $\begin{array}{l}\text { The most common benign neoplasm of the spleen (incidence: } \\
0.02-0.16 \%) ; \text { also known as splenic angioma } \\
\text { For general details } \rightarrow \text { see Chap. } 117\end{array}$ \\
\hline Littoral cell angioma & $\begin{array}{l}\text { This tumor can be found only in the spleen } \\
\text { For details } \rightarrow \text { see Chap. 156 }\end{array}$ \\
\hline Hemangioendothelioma & For general details $\rightarrow$ see Chap. 116 \\
\hline Angiosarcoma & $\begin{array}{l}\text { Rare but still the most common non-lymphoid malignancy of } \\
\text { the spleen. } \\
\text { For general details } \rightarrow \text { see Chap. } 25\end{array}$ \\
\hline $\begin{array}{l}\text { Inflammatory myofibroblastic } \\
\text { tumor }\end{array}$ & For general details $\rightarrow$ see Chap. 133 \\
\hline
\end{tabular}

